\title{
A Case Report On Revenge Murder
}

\author{
*Dr. SandipMukhopadhyay,MBBS, **Dr. SayakSovanDatta,MBBS, \\ ***Dr.KaushikGhosh,MBBS, DPM, ****Dr. SayanBisaws, MBBS, *****Dr. \\ BiplabShee,MD, $* * * * * *$ Prof. (Dr.)BiswajitSukul, MD \\ ${ }^{1,2,3,4}$ Post-graduate trainee, Upgraded department of Forensic \& State Medicine, Medical College, Kolkata . \\ ${ }^{5}$ Assistant Professor, Upgraded department of Forensic \& State Medicine, Medical College, Kolkata . \\ ${ }^{6}$ Prof. \& Head, Upgraded department of Forensic \& State Medicine, Medical College, Kolkata .
}

\begin{abstract}
Even though ancient literatures suggest a link in between modus operandi of different crimes in different parts of universe, but there is a wide variation in motive and execution of crime in practical scenario. The object of this case presentation is to create awareness among the forensic experts on how a motive can influence the execution of crime. Sometimes there is a tendency on the part of the accused to mask the identity of the victim and thus escapes conviction as reflected in the following case. When a dead body is recovered from an aquatic situation and especially in a state of advance decomposition, the dead body gets worked upon by the aquatic animals, so that the identity becomes difficult to establish. It is a challenge on the part of Forensic Experts to distinguish whether the damage had been done in an attempt to mask the identity of the victim by the assailant or it is the process of activities of the aquatic animals (a post mortem artifact). In the following case a dead body was recovered in a state of advance decomposition with maggots all around the body where a portion of the face was removed along its whole circumference in an attempt to conceal the identity.
\end{abstract}

KeyWords: Modus operandi, Motive, Identity, Advance decomposition, Aquatic animals, Post mortem artifact, Maggots, Conviction.

\section{Introduction}

A revenge murder is defined as a situation wherekilling of a person being committed in an attempt to take revenge out of him or her. There is a wide variation in the modus opperendi of revenge murder where execution is governed by the motive of killing on the part of the assailant. Literature has cited many examples where a dead body is being worked upon by different means by the assailant after killing. It may take the form of inflicting multiple injuries exceeding more than what is required to kill a person, sometimes referred to as over killing, establishment of sexual relationship after death as in Hetal Parekh case. Even it takes the worst form when an assailant goes on eat up the flesh of the deceased in an attempt to fulfill irresistible impulse of revenge. Sometimes the assailant produces gross degree of mutilation on the dead body or produces such a gross disfigurement on the important body parts particularly the face in an attempt to obscure the identity of the deceased thus escapes conviction.

Among the several objectives of doing a post-mortem examination by the experts of forensic medicine are to establish the identity of the person, to reconstruct the scene of crime as well as reconstruction of the mental state of the assailant and the deceased before the crime and thus aid justice. When a dead body is recovered after a certain period of time following death and particularly when in a state of advanced decomposition the whole body is blotted so the identity of the person becomes very difficult to establish. In situations when a body is recovered from a aquatic environment and in a state of advanced decomposition the easily peeled-off epidermis aided with effects of aquatic animals on the dead body possess even a greater challenge for the forensic expert to form an opinion regarding those issues in a concrete manner. The following case is a perfect example of revenge murder where there was an effort made on the part of the assailant to mask the identity of the deceased and challenges faced by the experts to form an opinion due to the natural process of advanced decomposition and effects of maggots and aquatic animals.

\section{Case Report}

A female body of apparent 16-18yrs of age was referred from SeramporeWalsh Hospital in a state of advance decomposition with maggots all over the body with generalized blotted appearance and a creamcolouredsalwar on the top. As per information furnished in its inquest report, the girl was missing for last 7 days. The body was recovered from an aquatic place at the nearby country side. At the time of recovery the body was grossly swollen with skin of the entire face was stripped off. The body was then sent to Serampore Walsh Hospital, Hooghly and subsequently referred to Kolkata police morgue. A team of experts of Forensic medicine performed the autopsy of the body with the following positive reports. 


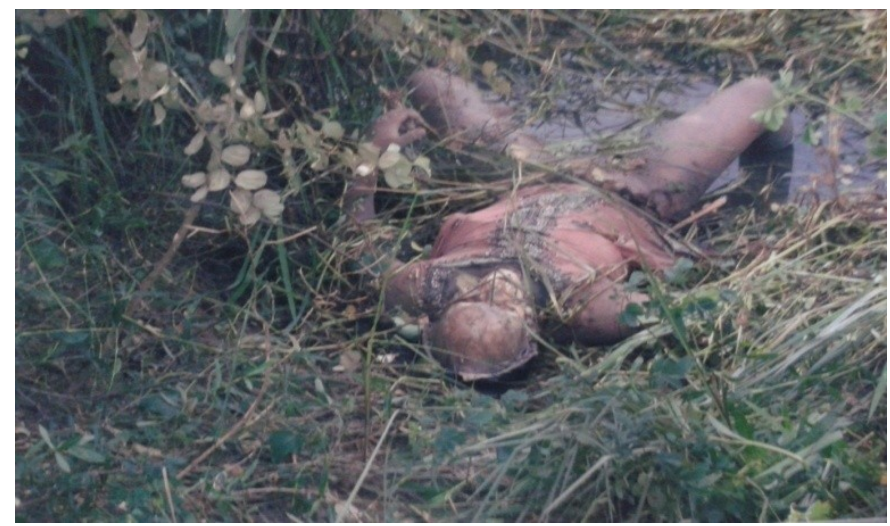

Fig (1): Body found at the place of occurrence

\section{External features:-}

$>$ Average built female body of 5'2" of approximate age of 16-18yrs in a state of advance decomposition .Rigor mortis passed off with peeling of epidermis and maggots all around the body.

$>$ Wearing apparels- Cream and black colour mixed churidar with underlying one brassiere. The lower part of the body was totally uncovered.

Injuries:-

One tattoo mark written as $\mathrm{R}+\mathrm{K}$ at the ventral aspect of left fore-arm.

$>$ One stab wound transversely placed at supra-sternal notch measuring 2 "x0.6" $\mathrm{x}$ air tube .

$>$ Another stab wound placed $1 / 2$ " abovethe previous one measuring 1.8 " 0.3 " 0 air tube .

$>$ Stab wound at the level of upper part of thyroid cartilage placed transversely measuring 3 " $\mathrm{x} 1 / 2$ " $\mathrm{x}$ extending up-to trachea with exposure of underlying air way structures.

$>$ One incised wound joining both the mastoid processes passing over the vertex with downward extension up-to supra-sternal notch involving whole facial skin circumferentially exposing facial skeleton and obscuring the total identity of the deceased.

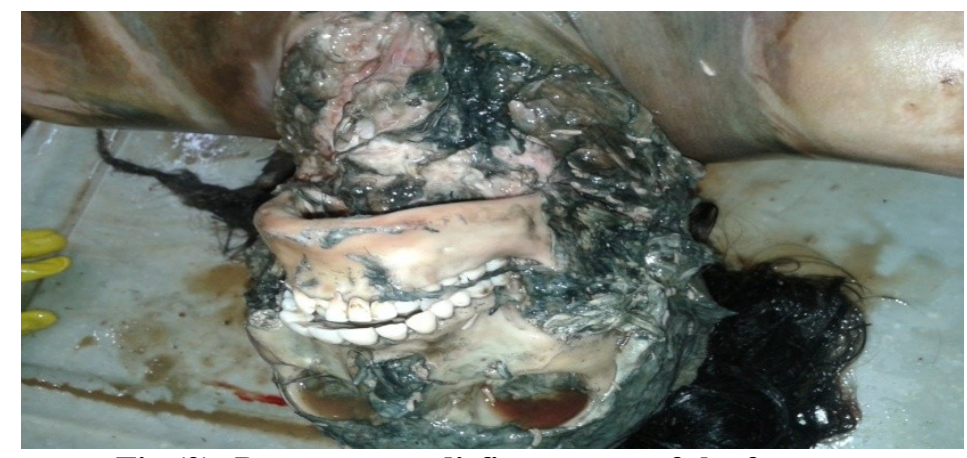

Fig (2): Post-mortem disfigurement of the face

$>$ One incised wound $2 " \times 0.5 " x$ muscle deep at the lateral aspect of right hand.

\section{Internal findings:-}

Showing nothing remarkable features as the process of decomposition took its full effect and maggot activities all around the body.

- Wearing apparels, scalp hair, nails, tooth is preserved for FSL with maintenance of proper chain of custody.

- With the above post-mortem findings the team of forensic experts come to an opinion that the death was due to the effects of stab injuries on vital airway structures, ante mortem homicidal in nature with 


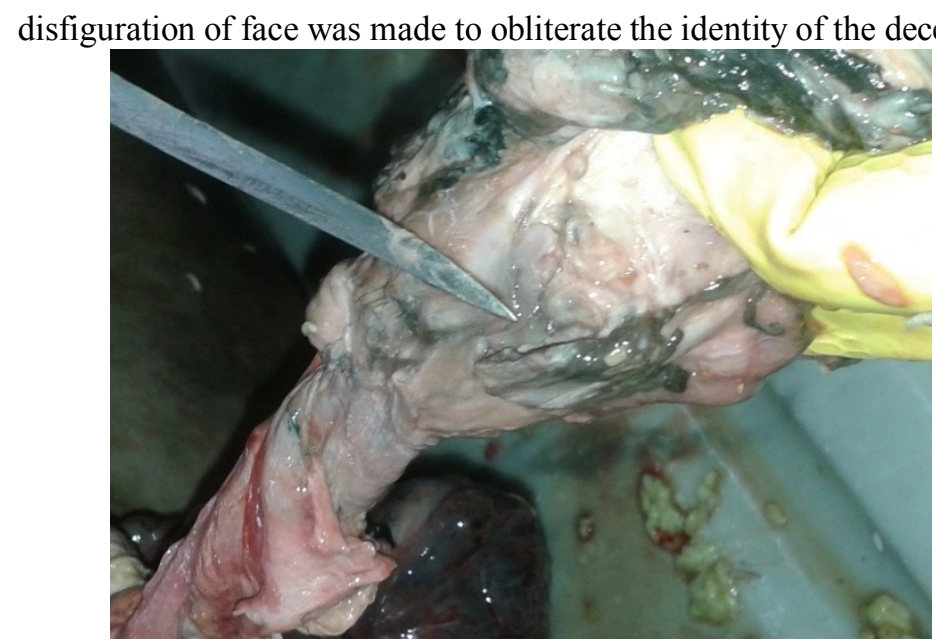

Fig (3): Incised wound over trachea

- Whether there was any sexual offence committed on the deceased could not be opined due to the effects of advance decomposition.

- Subsequent police investigation revealed that the deceased girl was in a relationship with the assailant whose name started with letter" K" as find out in tattoo mark of the deceased and he was a meat chopper by profession. But later the deceased refused to marry the assailant and she made another relationship. Following that to take revengethe assailant stabs her and took out the facial skin to conceal her identity.

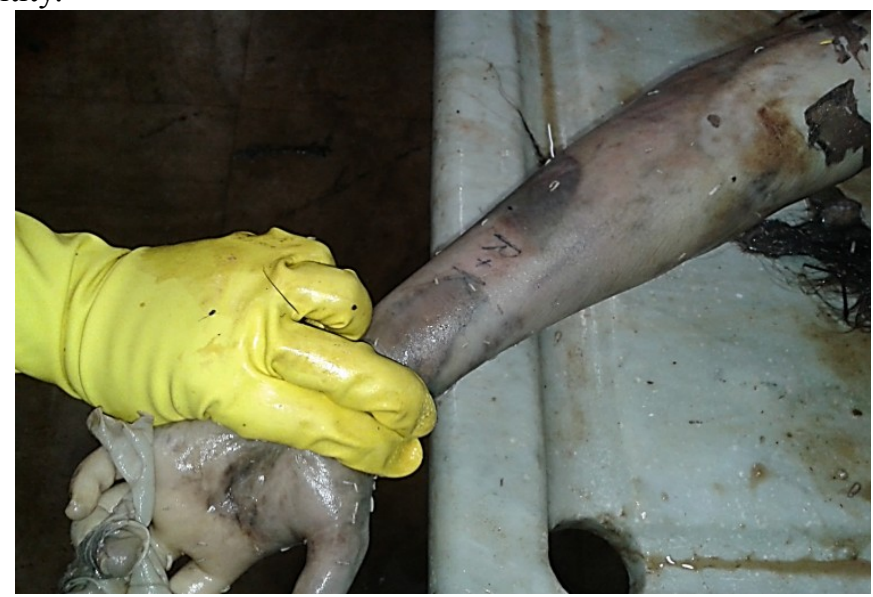

Fig (4): Tattoo on the volar aspect of left forearm showing " $R+K$ "

\section{Discussion}

The modern era has noticed a decrease in the level of tolerability and outbursts of aggressive violent behavior which has got a multi factorial origin. Even though the DSM-IV has not defined aggression clearly but as a working definition aggression is referred to the behavior intended to cause physical injury to others is descriptive by the virtue of its short term consequences that is harm to others. Now aggression and revengeful attitude is common in certain personality traits and mental disorders. The probability of aggression increases when a person becomes psychologically decompensate.

As per the instinctive behavioral theory by Sigmund Freud any human behavior stems from complex interplay of Eros-andThanatos instinct and the thanatos the death force. Where unrestrained thanatos leads to aggression and by the process of displacement is directed outwards that forms the violent behavior towards others. organisms.

As per Konard Lorenz, aggression springs from the fighting instincts men share with other wild

As per John Dotlards, frustration aggression hypothesis, aggression always stems from an underlying frustration, where direct provocation sometimes contributes to it.

Media often contributes to aggressive and violent behavior by a short term stimulating effect on a nascent criminal mind, by projecting the world more hostile than what actually is, by justifying violence and by giving ideas of Modus Operandi of crime. 
Now several situational factors like heightened physiological or sexual arousal and infliction of painful stimulus often leads to violent behavior.

Recent development in medical science has thrown some light regarding anatomical co-relation of aggression with orbito-frontal cortex plays an important role in socio-pathy and violent behavior. Studies showed that involvement of several neuro-chemicals like Testosterone, Progesterone, Luteinizing hormone, NA , Dopamine ,Serotonin ,5HIAA and Androgen are responsible for violent act.

FBI crime report in UK showed 1.5 million of crimes committed per year of which 90000 are rape and 15000 are homicide are committed annually. The situation is really alarming.

Homicides are prevalent in the lower socio-economic group and incidents are higher in urban and semiurban areas compared to rural areas.

Domestic violence, broken families, chaotic living condition often contributes to aggressive behavior.

\section{Conclusion}

From the above case report and discussion it is quite evident that the current situation represents a lower tolerability and aggressive behavior culminating into a revengeful attitude out of jilted love affairs. So it needs a holistic approach from different sectors of society to control this alarming issue. High risk population should be identified at the earliest and sent for psychological counseling to identify its violent or aggressive intent. Legislative measures should be applied properly to safe-guard the interest of the victims and society at large. Mass media should play an important role by creating awareness among the common people. The role of forensic experts is to perform the meticulous autopsy including psychological autopsy in suspected cases to help the judicial system.

\section{References}

[1]. BartholowB.D.,AndersonC.A,CarnageyN.L.,BenjaminA.J.jr "Interactive effects of Life Experience and Situational cases on aggression:Theweapons priming effects in hunters and non-hunters,Journal of Experimental Social Psychology" 2005;41,48-60

[2]. Ramirez J.M.,BonniotCabanac M.c.,Cabanac M. “Can aggression provide pleasure?”European psychologists 2005:10(2):136-145

[3]. Trembley R.E.,HartupW.W.,ArcherJ.Developemental Origins of Aggressions,NewYork:Guilford press :2005

[4]. Lenis Do,"Adult antisocial behavior,criminality and violence,lw:Sadock B J,Sadock V A,eds,Kaplan\&Sadock's Comprehensive Textbook of Psychiatry $8^{\text {th }}$ ed.vol 2 Baltimore:Lippincott Williams \&Wilkins :2005:2258 